\title{
Os atores locais como promotores de Desenvolvimento Territorial Endógeno
}

\author{
Alessandra de Sant'Anna ${ }^{1}$ \\ Gilson Batista de Oliveira ${ }^{2}$
}

\begin{abstract}
Resumo
Este artigo se propõe a discutir como os atores locais podem transformar o crescimento econômico em desenvolvimento a partir dos pressupostos da Teoria de Desenvolvimento Territorial Endógeno. Esta estratégia-ação se apresenta como uma alternativa ao pensamento neoclássico, que se expande a partir dos anos de 1970, em função da crise que perpassa os países, e como uma opção por uma internacionalização dos mercados e da economia como preconizados pela globalização. A Teoria do Desenvolvimento Territorial Endógeno prevê o fortalecimento do governo local como um espaço de fomento da economia, uma vez que os territórios possuem potencial para instituir sistemas e processos capazes de transformá-la, gerar conhecimento acerca das atividades econômica e produtiva da região, de modo a criar instrumental que a torne competitiva e apta a atrair investidores. As escolhas públicas que orientam o território no estabelecimento de seu planejamento regional, a capacidade de integrar atores locais diversos e a habilidade na produção de consensos fortaleceriam os capitais locais, o que se torna um fator crítico de sucesso tanto no que se refere ao desempenho econômico quanto à geração de bem-estar e melhores condições de vida no território. Este estudo, de abordagem qualitativa, baseia-se em uma revisão da literatura no âmbito das ciências econômicas, sociais e políticas, de modo a cumprir três objetivos específicos: resgatar o contexto de emergência e os pressupostos presentes no desenvolvimento territorial endógeno, apontar como os atores locais, enquanto agentes de desenvolvimento, convertem impulsos externos em desenvolvimento a partir dessa vertente econômica, e discutir como micro e macroeconomia se articulam nessa abordagem.
\end{abstract}

Palavras-chave: Desenvolvimento Territorial Endógeno. Atores Locais. Participação Social. Políticas Públicas. Planejamento.

\begin{abstract}
This article proposes to discuss how local actors can transform the external impulse of growth in development from the assumptions of the theory of endogenous territorial development. This action strategy presents itself as an alternative to neoclassical thinking that expands from the 1970s onwards, due to the crisis that permeates the countries and the option for an internationalization of markets and the economy as advocated by globalization. The theory of endogenous territorial development provides for the strengthening of local government as a space for economic development since territories have the potential to institute systems and processes capable of transforming the economy, generating knowledge about the economic and productive activity of the region to create instruments that make it competitive and able to attract investors. The public choices that guide the territory in establishing its regional planning, the ability to integrate diverse local actors and the ability to produce consensus would strengthen local capitals, which becomes a critical success factor both in terms of economic performance and in the generation of well-being and better conditions of life in the territory. This qualitative study is based on a review of the literature in the economic, social and political sciences to fulfill three specific objectives: to rescue the context of emergencies and assumptions present in

\footnotetext{
${ }^{1}$ Mestranda em Políticas Públicas e Desenvolvimento, no Programa de Pós-Graduação em Políticas Públicas e Desenvolvimento da Universidade Federal da Integração Latino-Americana (PPGPPD/UNILA). Bolsista DS/UNILA. alessandradesantanna@gmail.com.

2 Doutor em Desenvolvimento Econômico. Professor do Programa de Pós-Graduação em Políticas Públicas e Desenvolvimento da Universidade Federal da Integração Latino-Americana (PPGPPD/UNILA). gilson.oliveira@unila.edu.br.
} 
endogenous territorial development, to point out how local actors agents of development convert external impulses in development from this economic side and discuss how micro and macroeconomics are articulated in this approach.

Keywords: Endogenous Territorial Development. Local Actors. Social Participation. Public Policies. Planning.

\section{Introdução}

Este estudo tem como objeto o desenvolvimento territorial endógeno ${ }^{3}$ e se propõe a discutir como os atores locais podem transformar em desenvolvimento o impulso externo de crescimento por meio da endogenia territorial.

É comum o tratamento de crescimento econômico como sinônimo de desenvolvimento econômico, contudo isto é um reducionismo. O aumento da produtividade e da produção de riqueza enquanto resultado da expansão na produção de bens e serviços e da produtividade da força de trabalho, somadas à acumulação de capital e à inovação enquanto sinônimo de progresso tecnológico - não implica, necessariamente, a presença de desenvolvimento em uma determinada região/território/sociedade. O desenvolvimento deriva do conteúdo das escolhas públicas e da capacidade dos agentes locais (públicos e privados) estabelecerem arranjos políticos entre os diferentes segmentos de atores presentes no território. Boisier (1989) sinaliza para o esforço desprendido pelas sociedades no cumprimento de certos ideais relacionados ao desenvolvimento, os quais se vinculam com a produção e reprodução da base econômica de seu sistema social, oferta de padrões sociais estáveis, visando à garantia da integridade do território.

O desenvolvimento territorial endógeno requer, nos termos de Oliveira e Lima (2003), que os elementos locais sejam privilegiados pelas políticas macroeconômicas que, ao longo dos esforços para promoção de desenvolvimento, primaria pelo aproveitamento pleno dos recursos humanos, ambientais e institucionais da região, e, ainda, consideraria os anseios da população, uma vez que, como aponta Oliveira (2002), o desenvolvimento é o crescimento aplicado na satisfação das necessidades humanas. O desenvolvimento territorial endógeno emerge como uma contraposição ao pensamento neoclássico, que

3 Neste trabalho, o desenvolvimento territorial endógeno será tratado no contexto da Teoria do Desenvolvimento Regional Endógeno, que, doravante, será nominada como Teoria do Desenvolvimento Territorial Endógeno, para melhor refletir nosso objeto de estudo: o território. 
ganha força nos anos 1950 e 1960, apropriado por Estados Unidos e Inglaterra, na década de 1970, e difundido para os países capitalistas periféricos, com especial ênfase aos países da América Latina, a partir dos anos 1990. O desenvolvimento territorial endógeno propõe uma alternativa ao ambiente de incerteza e ampla concorrência do mercado, com ênfase em uma mudança no modelo de Estado dos países, e, segundo Vázquez Barquero (2001), ele emerge no bojo de mudanças na economia, que passa por mudanças nas formas de organizar a produção - do modelo fordista de acumulação em massa para os modelos de produção flexível - bem como mudanças nas formas de regulação - de políticas tradicionais de caráter rígido para políticas de caráter flexível.

Nesse contexto, o desenvolvimento territorial requer a participação da sociedade nos processos de gestão dos territórios por meio de um planejamento participativo. Quanto maior a capacidade de a gestão absorver os interesses locais, maior será a capacidade de serem atendidas as necessidades humanas e os anseios da sociedade local, por meio da elaboração de políticas públicas capazes de atender às necessidades de crescimento econômico, sem negligenciar os impactos causados sobre a população, e elaborar ações de combate ou mitigação das desigualdades criadas pelo sistema produtivo e as necessidades geradas pelo mercado (VÁZQUEZ BARQUERO, 2001; OLIVEIRA, 2003).

A atenção aos anseios e interesses presentes no território conforma o conteúdo das políticas públicas. Mais que produto de consensos e pactuação, elas são o principal mecanismo de regulação de um território, posto que expressam os objetivos e metas presentes na localidade, dão o norte para os diferentes atores sociais em relação a uma determinada matéria, a qual atende a um problema público específico. Di Giovanni (2009) destaca o caráter evolutivo das políticas públicas, apontando que elas são uma forma de intervenção nas relações sociais, inclusive no âmbito da econômica, e expressam uma relação de poder. Villanueva (2012) concorda com este pensamento, embora opte pelo termo autoridade, e apresenta diferentes definições de políticas públicas, onde se verifica que a intencionalidade é um aspecto comum a todas. Há que se destacar que a intencionalidade se insere em um determinado espaço de tempo, porque a política pública é viva tal como as relações entre os atores sociais e tem sempre um propósito vinculado à garantia de estabilidade, seja ela política, social, econômica ou ambiental. 
Leonardo Secchi (2009) apresenta uma perspectiva multicêntrica na abordagem e tratamento das políticas, considerando que o governo e seu aparato administrativo não é a única instituição a servir a comunidade política, uma vez que ele se ocuparia das macropolíticas. Nesta perspectiva, a articulação dos atores na arena política local permitirá arranjos mais favoráveis aos interesses do território, facilitando o atendimento às especificidades de cada região.

Este artigo, que possui uma abordagem qualitativa, propõe-se a fazer uma revisão da literatura sobre desenvolvimento regional endógeno, de modo a resgatar o contexto de emergência e os pressupostos presentes no desenvolvimento territorial endógeno, apontar como os atores locais - enquanto agentes de desenvolvimento - convertem impulsos externos em desenvolvimento a partir desta vertente econômica, e discutir como micro e macroeconomia se articulam nessa abordagem. Os resultados do estudo estão organizados em três eixos.

Inicialmente, o que se propõe é pensar, inicialmente, sobre o "crescimento econômico e as teorias de desenvolvimento territorial", tomando-se por recorte a exogenia presente nas teorias clássicas da localização das atividades econômicas e nas teorias de desenvolvimento regional com ênfase nos fatores de aglomeração. Em seguida, em "Desenvolvimento territorial endógeno: conceito, pressupostos e abordagens", serão apresentados o contexto em que o conceito emerge, ressaltando a que ele busca responder, quais são os princípios e valores que carrega, bem como os autores que abordam essa temática percebem o território. Por último, o estudo se debruça sobre "Oos atores locais como mediadores dos interesses presentes no território e a macroeconomia", partindo-se do pressuposto de que é a ocupação dos atores sociais na arena política a principal responsável pela conversão do crescimento viabilizado pelas políticas macroeconômicas em desenvolvimento.

\section{Globalização, crescimento econômico e teorias do desenvolvimento territorial}

A partir dos anos 1970, ocorre o que Bresser Pereira (1998) denomina como "grande crise" e se refere a uma crise do Estado, que acomete tanto países capitalistas quanto os soviéticos, e que apresenta como principais efeitos a perda das capacidades estatais do 
ponto de vista econômico, fiscal, político e protetivo. Somando-se a este cenário, a globalização emerge como uma nova forma de gerir a economia mundial, orientada pela internacionalização dos mercados nas relações. Na análise do autor:

[...] a globalização levou a um enorme aumento do comércio mundial, dos financiamentos internacionais e dos investimentos diretos das empresas multinacionais. Significou, assim, um aumento da competição internacional em níveis jamais pensados e uma reorganização da produção a nível mundial patrocinada pelas empresas multinacionais (BRESSER-PEREIRA, 1998, p. 56).

A globalização, no entendimento de Neves et al. (2017), sinaliza para a adoção de novas estruturas e abordagens que orientam o desenvolvimento dos países, ressaltando-se a competitividade, a sustentabilidade e a adoção de boas práticas de governo. Concorrentemente ao processo de globalização, os países periféricos, em especial os da América Latina, sofrem um processo de reformulação do aparelho estatal, que passa a adotar pressupostos gerenciais oriundos do pensamento de Taylor e Fayol ${ }^{4}$.

No caso do Brasil, para além das dinâmicas econômica e política que marcam o contexto em que se aprofunda o debate sobre a globalização, emergem novos desafios no âmbito da gestão, principalmente para os municípios, que ganham maior protagonismo do ponto de vista administrativo, fiscal e tributário em função da descentralização, da Constituição Federal de 1988 e dos efeitos da Reforma do Aparelho do Estado brasileiro.

O protagonismo do governo local resulta da substituição do Estado desenvolvimentista do pós-segunda guerra, implicando o seu afastamento de sua identidade protecionista, como aponta Bresser Pereira (1998), e da promoção direta do desenvolvimento em suas dimensões social e econômica, bem como a adoção de um Estado regulador, facilitador e financiador que assume pressupostos gerenciais. Esta nova identidade estatal decorre de uma necessidade da globalização, a qual é definida, nos termos de Vázquez Barquero (2000a), como um processo que enfatiza a intensificação da concorrência nos e entre os mercados, por meio de novos arranjos produtivos; o

4 Amaru Maximiano (2015) aponta que tanto Taylor quanto Fayol pertencem à escola clássica. O primeiro propõe a administração científica com ênfase na eficiência, linha da qual saem os estudos sobre qualidade, como o sistema Toyota de produção e o modelo japonês, a reengenharia e redesenho de processos, seis sigmas e o ciclo PDCA - Planejamento, Desenvolvimento, Controle e Ação. Fayol se insere nos estudos sobre o papel dos gerentes e o processo de administrar linha em que se situam os processos da gestão de projetos e a universalização das funções como expressão dos trabalhos dos gerentes de projetos. 
recolhimento do Estado; e transfere ou compartilha com outros entes federativos e outros atores sociais, como o setor privado e a sociedade civil organizada.

Bresser Pereira (1998) destaca que a globalização requer a construção de um Estado forte, ainda que enxuto, mais barato e eficiente, ao mesmo tempo em que protege os seus cidadãos, agora cidadãos-consumidores. É no bojo deste enxugamento do governo central que estados e municípios, por meio de sua organização social, ganham relevância, na medida em que os territórios e regiões conquistam mais autonomia para fazer as suas escolhas, articulando as necessidades e recursos presentes no território, o que implica disparidades nos níveis de desenvolvimento dos territórios e regiões.

\begin{abstract}
Esse novo papel das administrações locais foi possibilitado pela mudança de estratégia das administrações centrais. Durante as décadas de 80 e 90, os governos centrais assumiram posições neoliberais, passaram a centrar a sua atuação na realização dos objetivos macroeconômicos (inflação e déficit público), reduzindo o alcance das políticas regionais e industriais. A pouca eficácia das administrações centrais do Estado no fomento à difusão das inovações e na criação de empregos abriu espaço para os governos locais e regionais na regulação dos processos de ajuste e reestruturação produtiva (VÁZQUEZ BARQUERO, 2001, p. 213).
\end{abstract}

Tais disparidades seriam superadas, na perspectiva neoclássica, a partir do crescimento da produção, o que garantiria, naturalmente, maior equilíbrio entre as regiões. Contudo, o que Pike, Rodriguéz-Pose e Tomaney (2006) observaram foi que a instabilidade das regiões derivava da influência das taxas de poupança, depreciação e crescimento populacional, bem como da inexistência de renda per capita constante. Assim, o que se verificou foi o deslocamento da produção para localidades que oferecessem melhores taxas em razão da aplicação dos meios de produção. Amaral Filho $(1999$, p. 41) destaca que é o pensamento de León Walras e seus estudos sobre os rendimentos constantes que permitem tratar como endógenos fatores anteriormente tidos como exógenos, "[...] o que levou fatores como capital humano, conhecimento, informação, pesquisa e desenvolvimento, etc. a dividirem com os tradicionais capital e força de trabalho a composição da função de produção agregada".

Para Vázquez Barquero (2001), ao se tornarem endógenos, os fatores propulsores do crescimento econômico passam a obter especial valor para a promoção de desenvolvimento 
desde as cidades. Não se pode considerar, a partir desse pensamento, que todas as cidades se desenvolverão da mesma forma.

As cidades convertem-se no espaço preferencial do desenvolvimento, uma vez que
é nelas que são tomadas as decisões de investimento e de localização da indústria
e dos serviços. Seu potencial de desenvolvimento dá-lhes condições de responder
aos desafios colocados pelo aumento da competitividade, vinculando os processos
de ajuste produtivo e organizacional à utilização dos recursos próprios, à difusão
das inovações e aos fortalecimentos das relações com outras cidades (VÁZQUEZ
BARQUERO, 2001, p. 23).

A desigualdade expressa pela (in)capacidade de alguns territórios e regiões produzirem desenvolvimento está presente no pensamento de Pike, Rodriguéz-Pose e Tomaney (2006), os quais destacam que a desigualdade entre as regiões pode ocasionar um "growth limbo", em português "limbo de crescimento", naquelas que apresentarem baixa competência, habilidade ou capacidade na produção de efeitos positivos derivados do crescimento econômico, ou, mais comumente, o que é denominado modelos de spillover, que seria derivado do aumento da produtividade das empresas. Em sua Teoria de Base de Exportação, Vázquez Barquero (2001) apropria-se da abordagem de Douglas North ao considerar que o desenvolvimento econômico nos territórios e regiões é influenciado pela qualidade e complexidade das instituições. A Teoria da Base de Exportação apresenta como principal ideia o fato de que o impulso de crescimento das atividades locais decorre de sua capacidade de exportação.

O crescimento econômico exige dois conjuntos de ingredientes: permissivos e implementadores. Os permissivos relacionam-se com a capacidade física da economia para crescer: recursos materiais e humanos e acumulação de capital. Os fatores implementadores seriam aqueles que dariam impulso à combinação dos fatores de produção para gerar produtos (SCHWARTZNAM, 1973, p. 14).

A ênfase no papel das empresas aponta para um pressuposto do pensamento neoclássico presente no pensamento de Romer, resgatado por Vázquez Barquero (2000a, 2000b;2001), para quem o crescimento territorial endógeno poderia ser caracterizado segundo duas tipologias: (a) modelos de spillover - que apontam para o efeito propulsor para outras empresas, em função do aumento da produtividade e do crescimento econômico derivado da aprendizagem-experiência, qualificação profissional e investimento em pesquisa e desenvolvimento; (b) modelo shumpeteriano, que reconhece o protagonismo 
do avanço tecnológico como gerador de efeitos positivos no crescimento econômico, porém substitui a ideia de uma concorrência perfeita pela noção de competitividade imperfeita presente na relação entre competitividade e rentabilidade do mercado, a partir do avanço na pesquisa e do desenvolvimento.

Vázquez Barqueiro (2001) aponta que, no modelo neoclássico, o crescimento econômico se vincula ao crescimento do produto regional, na medida em que se aumenta a capacidade de produção de um dado território ou região. Significa reconhecer que:

[...] os processos de desenvolvimento ocorrem em função do uso potencial e excedentes gerados localmente e, às vezes, podem contar também com recursos externos. Mas, em última análise, são as iniciativas e o controle exercidos pelos atores locais e a sociedade civil, através de suas respostas estratégicas, que contribuem para os processos de transformação de cidades e regiões (VÁZQUEZ BARQUERO, 2001, p. 10).

Pike, Rodriguéz-Pose e Tomaney (2006) apropriam-se da construção de Armstrong e Taylor (2000) para elaborar uma sistematização dos determinantes do crescimento do produto regional (Figura 1). Assim, sob a ótica neoclássica, o que possibilita que uma região obtenha crescimento do produto regional é o crescimento dos três fatores: capital social, mão de obra e progresso tecnológico.

Figura 1 - Os determinantes do crescimento do produto regional

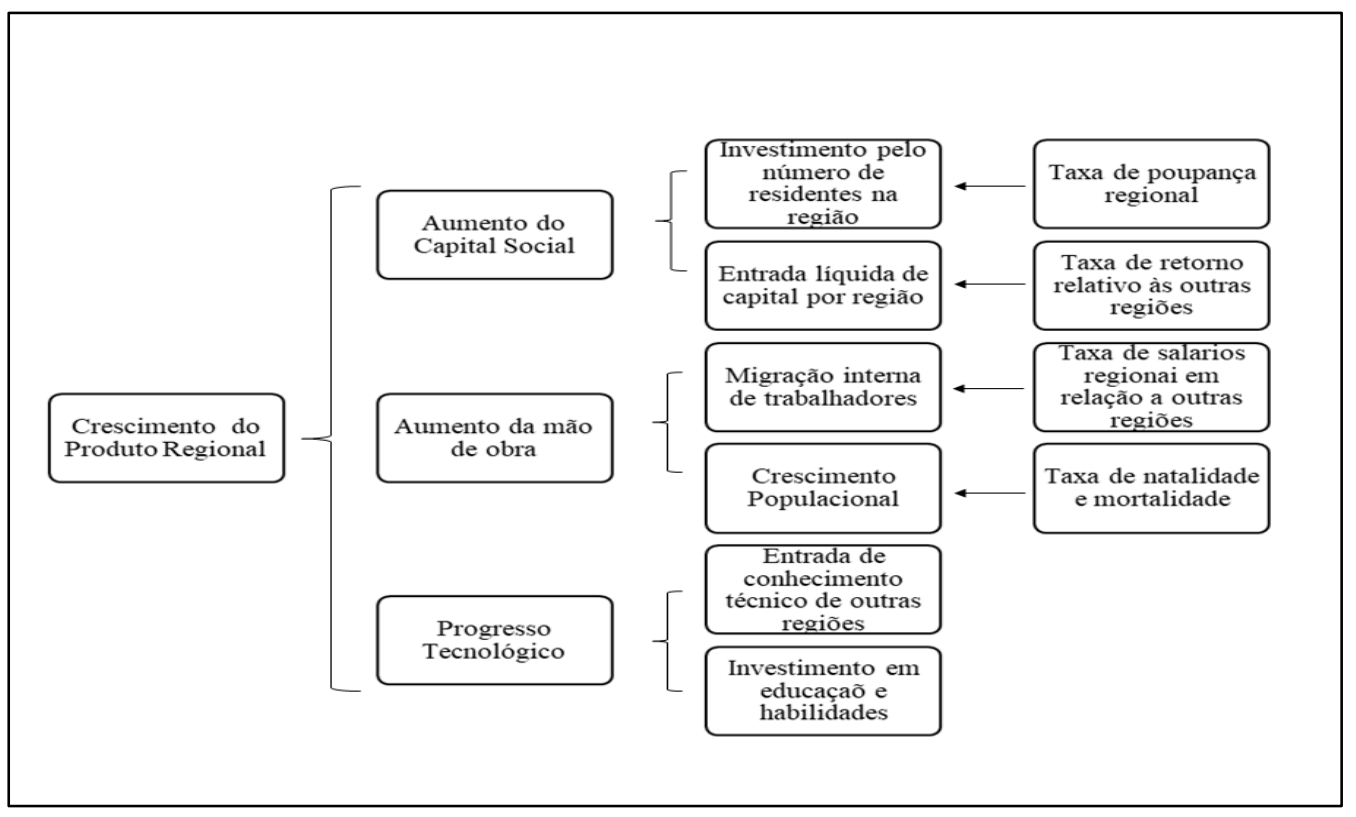

Fonte: Pike, Rodriguéz-Pose e Tomaney (2006, p. 63). Tradução nossa. 
Assim, a discussão sobre desenvolvimento territorial (Quadro 1) apresenta uma vertente caracterizada pela exogenia dos fatores de produção, que se dão tanto pela ênfase da localização das atividades econômicas (Von Thünen, Weber, Christaller e Losch) como um fator determinante para o crescimento econômico e promoção de desenvolvimento quanto pela ênfase nos fatores de aglomeração (PERROUX, MYRDAL, HIRSCHMAN E NORTH).

A concepção de desenvolvimento territorial endógeno emerge orientada por outros fatores, não palpáveis, mas que se encontram intrínsecos na sociedade local, assim como podem ser convertidos em vantagens comparativas para as regiões. Segundo Piacenti (2016, p. 64):

[...] nas décadas subsequentes, aspectos não tangíveis, fundados na cultura local, no comportamento da sociedade civil, na organização institucional e produtiva, bem como nas novas formas de competição e de cooperação, começam a ganhar importância na explicação do desenvolvimento regional ou local.

Há que se retomar um cuidado apontado por Oliveira (2002) em relação à adoção dos termos crescimento e desenvolvimento, e destacar que a Teoria do Crescimento Endógeno é diferente da Teoria do Desenvolvimento Endógeno. Vázquez Barquero (2001) sinaliza que as hipóteses que sustentam as duas teorias são diferentes. Da mesma forma, o modo como o desenvolvimento é induzido em cada uma das correntes econômicas também se diferencia ${ }^{5}$.

\footnotetext{
5 A Teoria do Crescimento Endógeno caminha entre os teóricos do pensamento neoclássico e dos teóricos do desenvolvimento territorial endógeno. Entre as críticas apontadas por Vázquez Barquero (2001) ao pensamento neoclássico, que acabam servindo de linha mestra para a adoção de um pensamento referenciado pela endogenia, estão as seguintes problemáticas: a forma como se dá o crescimento da economia, a relação estabelecida entre a taxa de crescimento e o nível da renda - na perspectiva endógena, não há relação -, a relação entre os impulsos exógenos, aumento da poupança e avanço de renda, que viabilizariam o crescimento endógeno.
} 


\section{Quadro 1 - Desenvolvimento Territorial - síntese das teorias exógenas}

\begin{tabular}{|c|c|c|c|c|c|}
\hline \multirow{9}{*}{ 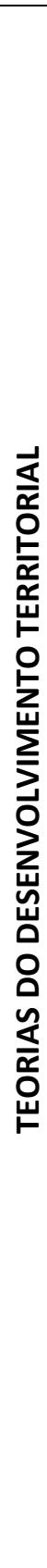 } & \multicolumn{2}{|c|}{ Caráter } & Teoria & Autor & Premissas \\
\hline & & & $\begin{array}{c}\text { Anéis de Von } \\
\text { Thünen }\end{array}$ & $\begin{array}{l}\text { Von } \\
\text { Thünen }\end{array}$ & $\begin{array}{l}\text { A maximização da terra deriva do } \\
\text { distanciamento das atividades } \\
\text { agrícolas do centro do mercado. }\end{array}$ \\
\hline & & & $\begin{array}{l}\text { Localização } \\
\text { industrial }\end{array}$ & Weber & $\begin{array}{l}\text { O custo de deslocamento é o que } \\
\text { determina a instalação ou não de } \\
\text { uma indústria em um território. }\end{array}$ \\
\hline & & $\begin{array}{l}\text { Teorias clássicas } \\
\text { da localização } \\
\text { das atividades }\end{array}$ & $\begin{array}{l}\text { Lugares } \\
\text { centrais }\end{array}$ & Christaller & $\begin{array}{l}\text { Os centros econômicos são o } \\
\text { ambiente naturalmente escolhidos } \\
\text { pelos espaços econômicos. }\end{array}$ \\
\hline & & econômicas & $\begin{array}{l}\text { Sistemas de } \\
\text { cidades }\end{array}$ & Losch & $\begin{array}{l}\text { As atividades econômicas estão no } \\
\text { centro das áreas de mercado e } \\
\text { preveem a uniformidade de escala e } \\
\text { custo de transporte. }\end{array}$ \\
\hline & 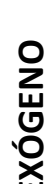 & $\begin{array}{c}\text { Teorias de } \\
\text { desenvolvimento }\end{array}$ & $\begin{array}{c}\text { Polos de } \\
\text { crescimento }\end{array}$ & Perroux & $\begin{array}{l}\text { O dinamismo entre as indústrias } \\
\text { evidencia sua capacidade de } \\
\text { produzir impulsos de crescimento. }\end{array}$ \\
\hline & & $\begin{array}{l}\text { regional com } \\
\text { ênfase em } \\
\text { fatores de } \\
\text { aglomeração }\end{array}$ & $\begin{array}{l}\text { Causação } \\
\text { circular } \\
\text { cumulativa }\end{array}$ & Myrdal & $\begin{array}{llr}\text { As desigualdades presentes nos } \\
\text { territórios derivam } & \text { do } \\
\text { aprofundamento das forças de } \\
\text { mercado. }\end{array}$ \\
\hline & & & $\begin{array}{l}\text { Efeitos para } \\
\text { frente e para } \\
\text { trás }\end{array}$ & Hirschman & $\begin{array}{l}\text { O crescimento econômico é desigual } \\
\text { e gera efeitos positivos e negativos. } \\
\text { O desenvolvimento de um território } \\
\text { é resultado da prevalência dos } \\
\text { efeitos positivos sobre os negativos. }\end{array}$ \\
\hline & & & $\begin{array}{c}\text { Base de } \\
\text { exportação }\end{array}$ & North & $\begin{array}{l}\text { O desenvolvimento de um território } \\
\text { é produto de sua capacidade de } \\
\text { exportação da região que, } \\
\text { inicialmente, dedica-se às atividades } \\
\text { econômicas básicas, que são motoras } \\
\text { de atividades complementares de } \\
\text { desenvolvimento. }\end{array}$ \\
\hline
\end{tabular}

Fonte: Elaborado pelos autores a partir de Piacenti (2016).

3 Desenvolvimento territorial endógeno: conceitos, contextos, pressupostos e abordagens

A crise dos anos de 1970, que, segundo o discurso neoliberal, expressava um esgotamento no modelo desenvolvimentista de Estado e a perda de suas capacidades estatais, apontou também para a emergência de novos paradigmas de desenvolvimento 
econômico centrados na endogenia. De modo concreto, o que se verifica é que essa crise levou ao enfraquecimento da atividade industrial, mesmo em regiões tradicionais, em contraposição à emergência de novos paradigmas industriais, como bem sinaliza Vázquez Barquero (2001), os quais levaram à ascensão econômica de novas regiões que, por meio da construção de um ambiente local favorável (entorno econômico, instituições e redes de cooperação), não apenas ocuparam novos mercados como também aumentaram sua competitividade nacional e internacionalmente.

O que se verifica é que, na esteira do debate sobre a globalização, nos anos 1980, há um aprofundamento também na análise das diferenças que marcam os países de economia central daqueles de caráter periférico. Há, portanto, um esforço dos economistas em exponenciar outras formas de pensar a economia para além do debate sobre crescimento econômico. Piacenti (2016) destaca que o conceito de endogenia consubstancia os termos desenvolvimento local, desenvolvimento regional e desenvolvimento territorial, presentes nos debates sobre teorias de desenvolvimento, os quais eram utilizados como sinônimos, embora cada um deles fosse dotado de identidade e aplicações específicas.

Se o pensamento neoclássico pontua que os fatores que levam ao desenvolvimento são exógenos ou externos à produção, uma vez que se referem ao crescimento populacional, taxas de poupança, capital humano e mudança tecnológica, as teorias neoclássicas, nos termos de Pike, Rodriguez-Pose e Tomaney (2006, p. 102), buscam "incorporar elementos formalmente externos e independentes em sua conceituação e explicação do crescimento econômico".

O desenvolvimento territorial endógeno apresenta uma perspectiva contrária, posto que sua linha de base é dada por fatores presentes na própria região ou território. Nos termos de Vásquez Barquero (2001, p. 67), “[...] os sistemas produtivos locais são formados por uma rede de agentes econômicos e sociais, estando baseada em um sistema de relações econômicas, sociais, políticas e legais capazes de estimular o crescimento e a mudança estrutural." Em outras palavras, é na dinâmica do território e na interlocução entre os atores que as escolhas públicas serão capazes de fazer convergir crescimento econômico em desenvolvimento. Trata-se, portanto, de um modelo de desenvolvimento orientado pelo paradigma "desde baixo", do qual Sthor e Taylor (1981) e Boisier (1989) são defensores. 
O pensamento de Sthor e Taylor (1981) se baseia em quatro pressupostos básicos: (a) as diferenças entre as regiões expressam os resultados de uma integração econômica em larga escala, desacompanhada de um planejamento regional capaz de mitigar os efeitos negativos desse crescimento; (b) não se pode pensar em desenvolvimento de curto prazo, motivo pelo qual é importante que o desenvolvimento não seja submetido aos interesses imediatistas do mercado e de outras influências externas, devendo sempre observar e acatar as especificidades do território no que se refere à sua cultura local e à natureza das instituições; (c) não existe a condicionalidade de que pequenas comunidades estejam vinculadas a outras regiões dotadas de maiores índices de desenvolvimento, uma vez que existe um potencial presente nas comunidades, mesmo as de pequenas escalas, as quais imprimirão os impulsos necessários à formulação e execução do desenvolvimento; e (d) o desenvolvimento apresenta como necessidade uma maior autodeterminação nacional e regional, as quais se expressam por meio de um planejamento regional.

O estabelecimento de um planejamento regional é um pressuposto do Estado gerencial e se apresenta como um instrumento de superação das disparidades próprias, tanto do ponto de vista geográfico quanto dos pontos de vista econômico, social e político. No Brasil, em 1995, o então Ministério do Planejamento e Orçamento já sinalizava para:

[...] a incorporação ao processo de planejamento de uma pesquisa aprofundada de esquemas de regionalização, em função da qual as atuais macrorregiões do país cuja grande extensão geográfica e consequente heterogeneidade de características físicas e econômicas não permitem uma intervenção mais apropriada do Governo - seriam divididas em sub-regiões, áreas-programa e áreas de desenvolvimento local, para as quais pudessem ser definidos programas governamentais mais adequados às especificidades de cada segmento do espaço regional (BANDEIRA, 1999, p. 9).

Na análise de Boisier (1989), os problemas oriundos da desconexão entre planejamento e desenvolvimento regional só poderiam ser resolvidos a partir de: (i) humildade para reconhecer os equívocos técnicos e conceituais, a fim de levar a abordagem do território por sua vertente física, excluindo-se a sua dimensão social; (ii) adoção de um novo instrumental capaz de responder às necessidades técnico-metodológica e de inovação presentes no território; (iii) elaboração de respostas de caráter coletivo, de modo a absorver 
os interesses dos atores locais ao mesmo tempo em que viabiliza aprendizagem social; e (iv) um novo paradigma de região, da região-objeto para a região-sujeito.

A adoção do desenvolvimento territorial endógeno não se limita à economia, porque é derivado da inter-relação de três forças: alocação de recursos, política econômica e ativação social. Com isso, o desenvolvimento decorre de uma rede de conhecimentos que deverão estar presentes no planejamento da região que concentra as ações a serem empreendidas rumo ao desenvolvimento. De acordo com Boisier (1989, p. 595-596):

[...] as propostas de desenvolvimento regional deverão ter dimensões sociais e políticas e firmarão suas raízes em demandas, não só de caráter econômico, senão que se nutrirão e, às vezes, estarão associadas a etnias, a culturas, em resumo, a movimentos sociais regionais muito diversificados. Em tal contexto, o trabalho de outros cientistas sociais, antropólogos, sociólogos, políticos etc., passará a converter-se em uma questão fundamental na formação das equipes de planejamento, tanto a nível central como local.

Neste sentido, o desenvolvimento territorial endógeno está ligado à capacidade da região em criar um sistema que identifique os macroparâmetros dos problemas presentes no seu território (diagnóstico socioterritorial), elabore linhas de ação capazes de atender ao ambiente sociopolítico concomitantemente às restrições ao valor das propostas (garanta legitimidade e estabilidade ao sistema). Tal compreensão torna-se mais nítida quando Piacenti (2016) destaca os objetivos da teoria que se debruça sobre a investigação e a compreensão da reciprocidade presente não apenas na interação ou na relação estabelecida entre economia e sociedade, mas também no crescimento econômico como resultado desta interação/relação.

Os diferentes capitais presentes no território, compreendido por Costamagna e Rozzi (2016, p. 18) como “[...] conjunto de atores e agente que o habitam com sua organização social e política, sua cultura e instituições" e que possibilitarão que se viabilize o desenvolvimento em suas diferentes dimensões no território. Boisier (1989) destaca que a organização social de uma dada instituição é determinada pelo estabelecimento de suas estruturas políticas, burocráticas e sociais, as quais permitam alcançar os estados ou dimensões do desenvolvimento.

Ainda sobre a capacidade de organização local, que é fundamental para entender como a dimensão do planejamento regional atua na viabilização e/ou potencialização 
das capacidades endógenas do território, Boisier (1989) destaca quatro pressupostos: (a) qualidade, capacidade e identidade da autoridade política da região - que se refere a quanto a localidade é capaz de produzir consensos, acordos, pactuações, de modo a garantir coesão entre os atores no território, legitimidade das escolhas feitas e estabilidade necessárias à construção/consolidação de um projeto de desenvolvimento médio/longo prazo; (b) qualidade da tecnocracia regional - que se refere ao grau de comprometimento das equipes técnicas responsáveis tanto pela assessoria quanto pela conversão/racionalização dos diferentes interesses presentes no território, nos planos de trabalho a serem implementados no âmbito dos territórios e regiões; (c) existência dinâmica e identidade da classe empresarial da região - responsável pelo uso dos efeitos positivos das políticas econômicas, o que faz com que seja produzido o crescimento necessário para que a sociedade local viabilize desenvolvimento por meio do (re) investimento destes recursos; e (d) existência de rede de agrupações ou estruturas sociais regionais - que se refere à capacidade de ativação social presente no território, de modo a criar espaços de participação, mobilizar atores sociais diversos (inclusive os mais pobres), porém unidos pelos interesses comuns, e habilidade em converter estes interesses em estímulos de crescimento.

Os quatro pressupostos apontados por Boisier (1989) são apropriados por Costamagna e Rozzi (2015), que aprofundam as dimensões a partir do tipo de ações a serem empreendidas pelos territórios na busca pela promoção de um desenvolvimento territorial que tenha por linha de base a endogenia (Quadro 2). 


\section{Quadro 2 - Dimensões do desenvolvimento territorial}

\begin{tabular}{|c|c|c|}
\hline \multirow{23}{*}{ 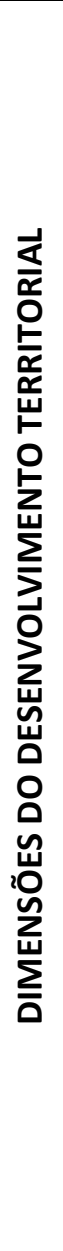 } & DIMENSÃO & AÇÕES A EMPREENDER NO ÂMBITO DO TERRITÓRIO \\
\hline & \multirow{5}{*}{$\begin{array}{l}\text { Desenvolvimento } \\
\text { Social e Humano }\end{array}$} & Acesso e melhoria da educação, formação, nutrição e saúde. \\
\hline & & $\begin{array}{l}\text { Melhora na distribuição de renda para a inclusão social e o } \\
\text { fortalecimento do mercado interno. }\end{array}$ \\
\hline & & Qualidade das relações de trabalho. \\
\hline & & Fortalecimento do papel da mulher na sociedade. \\
\hline & & Desenvolvimento de formas de economia social e solidária. \\
\hline & \multirow{6}{*}{$\begin{array}{c}\text { Desenvolvimento } \\
\text { Cultural, Político e } \\
\text { Institucional }\end{array}$} & Mobilização e participação cidadã. \\
\hline & & Fortalecimento dos governos locais. \\
\hline & & Coordenação de instituições públicas. \\
\hline & & Cooperação público-privada. \\
\hline & & Articulação social, criação de redes e capital social territorial. \\
\hline & & Fomento de cultura criativa e solidária. \\
\hline & \multirow{6}{*}{$\begin{array}{c}\text { Desenvolvimento } \\
\text { Econômico, } \\
\text { Tecnológico e } \\
\text { Financeiro }\end{array}$} & Fomento da diversificação e da qualidade produtiva no território. \\
\hline & & Infraestruturas básicas para o desenvolvimento territorial. \\
\hline & & $\begin{array}{l}\text { Serviços de apoio para pequenas e médias empresas e cooperativas } \\
\text { locais. }\end{array}$ \\
\hline & & Setor financeiro especializado territorialmente. \\
\hline & & $\begin{array}{l}\text { Sistema fiscal e marco jurídico e regulatório apropriado para o } \\
\text { fomento do desenvolvimento territorial. }\end{array}$ \\
\hline & & Fomento de sistemas territoriais de inovação. \\
\hline & \multirow{5}{*}{$\begin{array}{l}\text { Desenvolvimento } \\
\text { Sustentável }\end{array}$} & Valorização do patrimônio cultural como ativos do desenvolvimento. \\
\hline & & Fomento das energias renováveis. \\
\hline & & Uso eficiente de recursos, água, energia e materiais. \\
\hline & & Fomento da produção ecológica e da produção ecoeficiente. \\
\hline & & Fomento da produção local e das formas de consumo sustentáveis. \\
\hline
\end{tabular}

Fonte: Adaptado de Costamagna e Rozzi (2015, p. 19).

A partir dessas dimensões e ações a empreender, Vázquez Barquero (2001, p. 41) expõe que o desenvolvimento territorial endógeno está calcado na soma do crescimento econômico com uma mudança estrutural nas regiões, sob a gestão da sociedade local, que viabiliza um ponto comum "[...] pelo fato de os atores públicos e privados tomarem decisões de investimento que visam elevar a produtividade e a competitividade das empresas, solucionar os problemas locais e aumentar o bem-estar da sociedade."

A percepção de desenvolvimento territorial endógeno presente no pensamento de Vasquez Barqueiro (2001) se vale da análise de Boisier (1989) sobre a apropriação e exponenciação das vantagens comparativas óbvias pelo território. 
Uma região poderá ter vantagens comparativas óbvias na produção de bens de elevada demanda, porém, se não estiver presente um ator privado ou público, capaz de compreender, usar e transformar aquelas vantagens, elas continuarão registradas como um "potencial" de desenvolvimento, e este processo não será originado. Podemos chegar ainda mais longe, quiçá, em certos casos, se aquelas vantagens pudessem ser aproveitadas de forma eficiente e, mesmo nesse caso, a região continuaria em situação de atraso, devido a que uma ou outra política econômica nacional onera indireta e mais que proporcionalmente a região, em relação aos benefícios que obtém sua atividade produtiva (BOISIER, 1989, p. 610).

Outro aspecto presente na produção de Costamagna e Rozzi (2015) - e previamente sinalizado por Bortega et alli (2006) - refere-se à capacidade do território converter o próprio crescimento, via reinvestimento, em fatores determinantes para o seu crescimento. $O$ que os autores propõem é que o território seja capaz de estabelecer um círculo virtuoso de desenvolvimento, o qual ocorre, via planejamento, a partir da habilidade presente na região de "[...] investir em si própria os excedentes gerados pelo seu crescimento e desenvolvimento anteriores" (BORTEGA et al., 2006, p. 81). Tais pressupostos fazem com que o desenvolvimento territorial tenha no planejamento o seu principal parceiro.

\section{Os atores locais como mediadores dos interesses presentes no planejamento urbano e territorial}

Como ponto de partida deste tópico, apresenta-se uma discussão sobre o conceito de planejamento urbano e territorial. Para tanto, utiliza-se o trabalho do Programa das Nações Unidas para os Assentamentos Humanos (ONU-HABITAT, 2015, p. 2), que define o planejamento urbano e territorial como:

[...] um processo de tomada de decisões cujo objetivo seja atingir metas econômicas, sociais, culturais e ambientais por meio do desenvolvimento de visões espaciais, estratégias e planos, bem como a aplicação de um conjunto de princípios políticos, ferramentas, mecanismos institucionais e de participação e procedimentos regulatórios.

O planejamento urbano e territorial é capaz de absorver elementos endógenos de modo a potencializar a economia das localidades e gerar desenvolvimento. Oliveira (2002) destaca que o desenvolvimento deve produzir como efeito a melhoria da qualidade de vida das pessoas. É no território, na esfera local, que: 
[...] o planejamento urbano e territorial tem uma função econômica inerente e fundamental. Trata-se de um instrumento poderoso para reformular formatos e funções de cidades e regiões, visando gerar crescimento econômico endógeno, prosperidade e emprego, lidando com as necessidades dos grupos mais vulneráveis, marginalizados e carentes (ONU-HABITAT, 2015, p. 2).

Assim, sob a ótica da endogenia, tais ações produzirão um efeito em espiral capaz de intensificar e irradiar os efeitos positivos do crescimento econômico, viabilizando o desenvolvimento do território. Ao refletir sobre a alocação dos recursos nas regiões, Boisier (1989) destaca a necessidade de refletir sobre o planejamento que resulta da identificação e do estudo do problema que requer a intervenção, considerando a alocação de recursos escassos, dentro de um conjunto de objetos e metas que se espera alcançar, a partir de cinco categorias (eleição dos objetivos, eficiência no uso dos recursos, distribuição de oportunidades, modificação do poder e controle ecológico) originadas pela natureza do sujeito (jurisdição, país, região, província, distrito), o que determinará a tipologia do planejamento, que pode ser: (a) técnico-econômica; (b) espacial; (c) social; (d) política; e (e) ambiental.

O que se observa é que nesta lógica há um alinhamento entre os pressupostos do desenvolvimento territorial endógeno, os princípios apontados pelo ONU-HABITAT (2015, p. 8), em relação ao planejamento territorial e urbano, que confere protagonismo à dinâmica da região, considerando que o que se expressa no território é "um processo de tomada de decisões integrador e participativo que lida com interesses competitivos." Porém é a qualidade da governança no/do território quem permite estabelecer um ponto de convergência de interesses que são distintos, contraditórios e conflituosos, gerando uma resposta, via planejamento regional, que condense "uma estratégia geral de desenvolvimento de políticas urbanas [e/ou rurais] nacionais, regionais e locais" (idem). Adicionalmente, o mesmo documento destaca que a qualidade do planejamento é um componente estratégico para o estabelecimento de um "paradigma renovado de administração urbana" [e rural], que se expressa, por meio da democracia local e da participação, inclusão, transparência e responsabilidade.

Conforme vem sendo apontado, há, a partir dos anos de 1970, em contraposição ao pensamento neoclássico, uma corrente na economia que adota princípios endógenos, os 
quais preconizam o fortalecimento da esfera local e apontam para a adoção de políticas orientadas pelo paradigma "desde-baixo". Ferreira (2018) destaca que este é um momento de efervescência de técnicas colaborativas de desenvolvimento justamente quando o Estado visa identificar e fomentar as potencialidades das regiões e dos territórios. Para Vázquez Barquero, (2001, p. 30):

[...] quando um território é caracterizado por um sistema avançado de relações entre empresas e organizações e possui uma dinâmica própria de aprendizagem, a concorrência e a cooperação entre empresas convertem-se em elementos que contribuem para o desenvolvimento local.

O potencial dos territórios está nas formas de capital que ele consegue gerar e potencializar. Piacenti (2016) sinaliza a existência de cinco formas de capital que são decisivas no processo de promoção de desenvolvimento local: (a) capital institucional - que se refere à natureza e qualidade das instituições ou organizações presentes no território, sejam elas de caráter público ou privado; (b) capital humano - que se expressa pelo volume de conhecimento, competências e habilidades das pessoas que residem na localidade, bem como pela capacidade que o território tem de absorvê-las; (c) capital cívico - que observa do ponto de vista da adoção de práticas democráticas, onde se expressam os níveis de confiança nas instituições e a capacidade de estabelecer pactos e associações entres os atores locais; (d) capital social - que expressa os níveis de confiança e cooperação entre os membros de um determinado território; e (e) capital sinergético - que aponta os níveis de aptidão - expressos ou latentes presentes no território - de articular esforços para articular o capital intangível presente na sociedade.

Boisier (1989, p. 611) destaca que o desenvolvimento de uma região ou território depende do quanto ele participa na apropriação dos recursos nacionais. Esta participação somada aos recursos próprios da região "é o determinante principal do crescimento econômico regional." Um segundo aspecto que aponta para o potencial dos territórios refere-se aos efeitos das políticas macroeconômicas e setoriais, que Boisier denomina como "implícitos ou indiretos", que poderão ter, no processo de desenvolvimento territorial, status de coadjuvante ou contraproducente, que implica na anulação dos efeitos positivos. 
Por último, o conjunto de elementos políticos, sociais e institucionais reflete a capacidade de um território se organizar socialmente.

Amaral Filho (1999) destaca que o tipo ideal do desenvolvimento endógeno se associa a um modelo de desenvolvimento dependente do paradigma societal gerado no seio da formação social local ou regional. A internalização do crescimento e a conversão em desenvolvimento, no âmbito dos territórios e regiões, depende da organização social dos territórios, o que implica reconhecê-los como arena política, posto que neles habitam diferentes atores, os quais carregam diferentes interesses que, por sua vez, acabam por orientar a forma como se relacionam no território. Parte-se, pois, do entendimento de que territórios são arenas políticas e que as políticas públicas ali identificadas, pactuadas, implementadas e, em certos casos, reorientadas expressam os níveis de organização social necessários ao desenvolvimento territorial endógeno.

Há uma distinção feita por Paiva (2013) em relação ao território-foco x territóriorelevante para a reflexão sobre as regiões enquanto organizações promotoras de desenvolvimento. Um território foco é aquele que ativa socialmente o território no sentido de que dele parte o movimento inicial e, em alguns casos, a manutenção dos interesses dos atores no sentido de promover desenvolvimento. O território relevante é aquele que concentra as atividades propulsoras de desenvolvimento.

Quando o território-foco já é uma região composta por um conjunto de municípios, o território-relevante pode ser igual, maior, menor ou simplesmente distinto do território-foco. Neste caso, usualmente, o território relevante será multiescalar, envolvendo tanto a redivisão da região da região originalmente proposta, quanto a incorporação de novas áreas com as quais a região apresenta solidariedade dinâmica, mas que foram indevidamente excluídas da regionalização inicial (PAIVA, 2013, p. 70).

O território é o espaço onde se situam os macroparâmetros apontados por Boisier (1989), que consistem em elementos sobre os quais se deve debruçar por ocasião do planejamento do desenvolvimento regional: alocação de recursos, políticas públicas (econômicas e setoriais) e ativação social, considerando que a interação entre estes três elementos e, sobretudo, o reconhecimento de que os dois últimos determinam a forma de aplicação do primeiro, sendo este o movimento que determina a alocação de recursos. Por outro lado, a quantidade de recursos alocados influencia as políticas públicas (econômicas e 
setoriais) e a ativação social. Destaca-se, ainda a partir de Bobbio (2000; 2007), que cada um destes elementos interage entre si no âmbito do território enquanto arena política, estabelecendo nestes espaços uma relação de poder que se manifesta nos territórios por meio da atuação do Estado.

Quando enfatizamos a forma como interagem esses três fatores, damos também privilégio ao papel das instituições e dos grupos sociais no desenvolvimento regional. Destaca-se, assim, o papel de dois atores fundamentais: o Estado e a região, esta última pensada não apenas como um fato geográfico, mas como um ator social do processo de planejamento. O desenvolvimento de uma região depende, em último termo, de acordos, transações, conflitos, capacidade de negociações e, em definitivo, de articulação mutável, que aparece entre esses atores em momentos históricos determinados (BOISIER, 1989, p. 678).

A lógica presente na relação que se estabelece entre políticas públicas (econômicas e setoriais), ativação social e alocação de recursos no território pode ser expressa da seguinte forma (Figura 2).

Figura 2 - Funções, dimensões e retroalimentação no planejamento regional

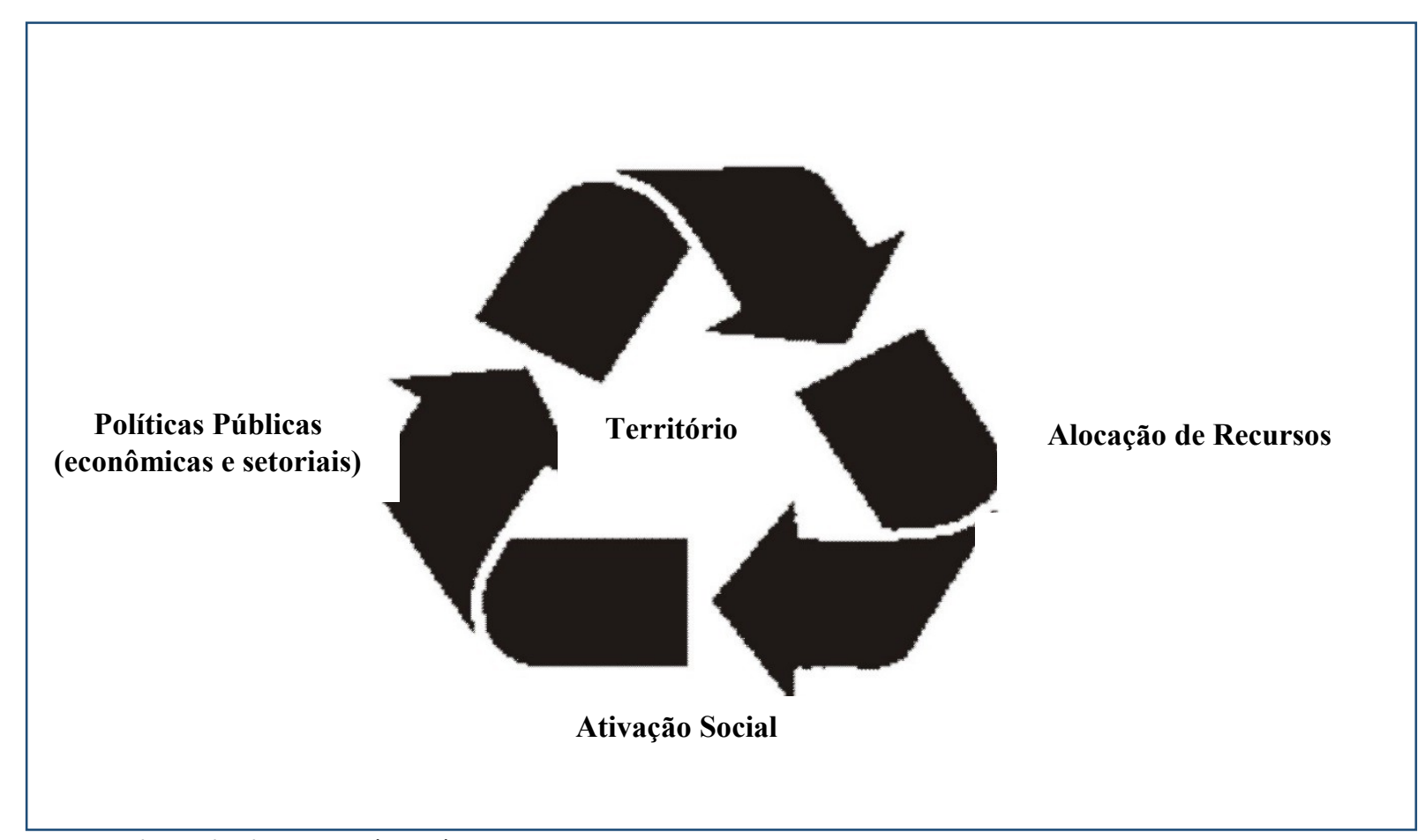

Fonte: Adaptado de Boisier (1989)

Não se pode afirmar que a sociedade local pode converter crescimento econômico em desenvolvimento territorial, sem considerar o papel da democracia como ordenamento 
para a dinâmica das relações travadas no âmbito de um território, o que possibilitará a interação entre ativação social, políticas públicas - sejam elas de caráter econômico e/ou setoriais -, e alocação de recursos. Nesse sentido, é importante retomar a definição de democracia apontada por Bobbio (2000), para quem democracia é uma forma de governo em que o poder não se apresenta de forma concentrada, mas diluída, e, por este motivo, pode ser acessado pela maior parcela da sociedade. Esta perspectiva é importante para destacar que a qualidade das escolhas públicas será dada pelo grau de diversidade e representatividade expresso pela participação social dos atores locais nos espaços de diagnóstico, tomada de decisão e controle das políticas públicas.

Outro aspecto da participação social que agrega valor ao desenvolvimento territorial endógeno está no fato de que os atores locais produzem conhecimento. Este é um importante ativo, visto por Vázquez Barquero (2001) como bem público, o qual precisa ser potencializado nos territórios. O processo de conversão de interesses individuais em coletivos dos atores locais, necessários à promoção de desenvolvimento territorial endógeno, como bem apontam Costamagna e Larrea $(2017,47)$, é marcado por tensões e se desenvolvem em um ambiente marcado por complexidades, posto que expressam diferentes visões de mundo.

\footnotetext{
Não há individual sem coletivo, nem coletivo sem individual. Cada um de nós atuamos em função da interpretação que fazemos da organização, do projeto, do município, do país, do mundo de que somos parte. A relação entre sujeito e objeto. A relação entre sujeito e a sociedade envolve uma complexidade que se apresenta como irredutível às categorias do todo e das partes. Nem a organização é mera soma de indivíduos, nem o território é mera soma de indivíduos e organizações. Da mesma forma, as capacidades coletivas do território em que se centra nossa proposta vão além da soma de capacidades dos indivíduos e das organizações (TRADUÇÃO NOSSA).
}

Bandeira (1999) destaca cinco argumentos que fundamentam a participação dos atores locais nas ações de produção de desenvolvimento: (a) a necessidade de conhecer os segmentos alcançados pela comunidade diretamente afetados pelos problemas públicos, os quais se constituirão em destinatários das políticas públicas, as quais refletem os resultados das disputas de interesses presentes no território e os valores presentes nos processos de tomada de decisão; (b) a boa governança para o desenvolvimento participativo, expressando os níveis de transparência das ações e a legitimidade dos processos no âmbito do território; 
(c) a participação social, que expressa os índices de confiança e de colaboração presentes na comunidade - seu capital social - e permite explicar por que algumas regiões se desenvolvem mais ou menos que outras; (d) o potencial criativo e de inovação do território, que é potencializado ao se conectarem mecanismos participativos na formulação e implementação das políticas públicas, o que impulsiona a competitividade da região; e (e) a produção de consensos e pactuações necessárias ao desenvolvimento do território, potencializada por meio da construção e do fortalecimento da identidade regional.

\footnotetext{
Diferenças na forma de ver o social a partir dos não sociais, o econômico por parte dos não economicistas, o olhar dos empresários sobre os políticos e dos políticos sobre os empresários, dos geradores de conhecimento sobre ambos (empresários e políticos) e vice-versa. E aí aparecem novos cenários e começamos a vivenciar a construção de um desenvolvimento territorial que contemple a economia, a política, as instituições, a cultura, as cidades, os setores com direitos vulneráveis, as leis, os níveis de governo (municipal, provincial e nacional), América Latina e mundo (COSTAMAGNA; LARREA, 2017, p. 46. TRADUÇÃO NOSSA).
}

Uma das formas de abordar desenvolvimento territorial é a de que ele deriva da capacidade da sociedade local em estabelecer boas governança e gestão do e no território, o que se expressa por meio da criação de uma estrutura de sistemas e equipamentos ali presentes, capazes de identificar e impulsionar os efeitos positivos do crescimento. $\mathrm{O}$ estabelecimento de consórcios de equipamentos públicos, a elaboração de redes e a instauração de inovações na gestão são exemplos que expressam como a sociedade local gera possibilidades de criar impulsos positivos capazes de converter o crescimento econômico de um território em desenvolvimento territorial endógeno.

\section{Considerações finais}

A Teoria do Desenvolvimento Territorial Endógeno é uma teoria econômica que emerge com o objetivo de preencher as vacâncias no pensamento neoliberal, que, em seu aprofundamento, deixa descoberta a capacidade dos territórios de produzir riquezas e contribuir para a melhoria das condições de vida da população a partir de fatores de produção presentes na própria região. No Brasil, a descentralização dos poderes políticos e administrativos e o federalismo no financiamento são mecanismos que acabam por legitimar 
a ênfase à conjugação dos três elementos necessários ao desenvolvimento territorial endógeno: alocação de recursos, políticas públicas (econômicas e setoriais) e ativação social.

O principal desafio para a produção de desenvolvimento territorial endógeno está na qualidade do planejamento regional urbano, que, para além de elaborar um diagnóstico claro, produzir conhecimento e viabilizar inovações no âmbito do território, constitui-se em uma ferramenta capaz de (re)alocar os escassos recursos derivados do crescimento econômico em ações capazes de integrar os anseios dos atores locais presentes nos territórios - os quais são expressos pela construção de objetivos claros e metas alcançáveis , distribuir oportunidades, poder e estimular o controle. Cabe destacar que tal tarefa não é fácil, uma vez que pressupõe a criação de uma identidade coletiva, regional, a qual expressa os níveis de capital institucional, humano, cívico, social e sinergético presentes no território.

Ainda há muito o que estudar e problematizar sobre essas questões, tanto pelo aspecto histórico e territorial dos arranjos feitos pelas sociedades em sua busca pelo desenvolvimento quanto pela infinidade de novas estratégias de desenvolvimento territorial que podem emergir no âmbito do território.

\section{Referências}

ARMSTRONG, H; Taylor, J. Regional Economics and Policy. Oxford: Blackwell, 2000.

AMARAL FILHO, Jair do. Desenvolvimento Regional endógeno em um ambiente federalista. In: Planejamento e Políticas Públicas. n. 14, dez., p. 35-74, 1996.

AMARU MAXIMIANO, Antonio Cesar. Introdução à Teoria Geral da Administração. 3. ed. São Paulo: Atlas, 2015.

BANDEIRA, Pedro. Participação, articulação de atores e desenvolvimento regional. In: Textos para discussão n. 630. Brasília: IPEA, 1999.

BOBBIO, Norberto. Estado, Governo e Sociedade: para uma teoria geral da política. Tradução de Marco Aurélio Nogueira. 14. Ed. São Paulo: Paz e Terra, 2007.

BOBBIO, Norberto. Liberalismo e democracia. Tradução de Marco Aurélio Nogueira. São Paulo: Brasiliense, 2000. 
BOISIER, Sérgio. Política econômica, organização social e desenvolvimento regional. In: HADDAD, Paulo Roberto (org.). Economia regional: teorias e métodos de análise. Fortaleza: BNB; ETENE, 1989.

BORTEGA, Erica Karla et al. Industrialização e desenvolvimento regional: notas para reflexão. In: Revista FAE. v. 9, n.2, jul./dez. 2006.

BRESSER PEREIRA, Luiz Carlos. A reforma de Estado nos anos 90: lógica e mecanismos de controle. In: Lua Nova. n. 45, p. 50-95, 1998.

COSTAMAGNA, Pablo Santiago; ROZZI, Sérgio Pérez (orgs.) Abordagem, estratégia e informação para o desenvolvimento territorial: as aprendizagens do ConectaDEL. ConectaDEL: FOMIN: BID, 2015.

COSTAMAGNA, Pablo Santiago; LARREA, Miren. Actores facilitadores del desarrollo territorial: una aproximación desde la construcción social. Orkestra, 2017.

DI GIOVANNI, Geraldo. As estruturas elementares das políticas públicas. In: Cadernos de Pesquisa n. 82. Campinas: UNICAMP, 2009.

FERREIRA, RENNAN. CODEFOZ: um caminho para o desenvolvimento regional endógeno. Dissertação (Mestrado) - Universidade Federal da Integração Latino-Americana, Foz do Iguaçu, 2018.

HADDAD, Paulo Roberto; FERREIRA, Carlos Maurício de Carvalho; ANDRADE, Thompson Almeida. In: Economia Regional: teoria e métodos de análise. Fortaleza: Banco do Nordeste do Brasil S.A.; Escritório Técnico de Estudos Econômicos do Nordeste, 1989.

NEVES PEREIRA, Fernando et al. Nova Gestão Pública e Nova Governança Pública: uma análise conceitual comparativa. In: Revista Espacios. n. 7, v. 38, 2017.

OLIVEIRA, Gilson Batista de. Uma discussão sobre o conceito de desenvolvimento. In: Revista FAE. v.5, n.2, maio/ago., 2002.

OLIVEIRA, Gilson Batista de; LIMA, José Edmilson de Souza. Elementos endógenos do desenvolvimento regional: considerações sobre o papel da sociedade local no processo de desenvolvimento sustentável. In: Revista FAE. v. 6, n. 2, maio/dez., 2003.

PAIVA, Carlos Águedo Nagel. Fundamentos da análise do planejamento de economias regionais. Foz do Iguaçu: Parque Itaipu, 2013.

PIACENTI, Carlos Alberto. Indicadores do potencial de desenvolvimento endógeno dos municípios paranaenses no período de 1999/2013. Foz do Iguaçu: Parque Itaipu, 2016. 
PIKE, Andy; RODRIGUÉZ-POSE, Andrés; TOMANEY, John. Concepts and theories of local and regional development. In: PIKE, Andy; RODRIGUÉZ-POSE, Andrés; TOMANEY, John. Local and regional development. Abingdon: Oxon, Routledge, 2006.

PROGRAMA DAS NAÇÕES UNIDAS PARA OS ASSENTAMENTOS HUMANOS - ONU HABITAT. Diretrizes internacionais para o planejamento urbano e territorial. Quênia: ONU HABITAT, 2015.

SCHWARTZMAN, Jacques. O desenvolvimento da teoria da base de exportação como uma teoria do desenvolvimento regional. Dissertação (Mestrado) - Universidade Federal de Minas Gerais, Minas Gerais, 1973.

SECCHI, Leonardo. Políticas Públicas: conceitos, esquema de análise, casos práticos. 2. ed. São Paulo: Cengage Learning, 2015.

STHOR, W. B.; TAYLOR, D. R. Development from above or below? The dialetics of regional planning in development countries. New York: John Willey and Sons, 1981.

VÁSQUEZ-BARQUERO, Antonio. Desarrollo económico local y descentralización: aproximación a un marco conceptual. Chile: CEPAL, 2000b.

Desarrollo endógeno y globalización. In: EURE. n.79, 2000a.

. Desenvolvimento endógeno em tempos de globalização. Porto Alegre: Fundação de Economia e Estatística, 2001.

VILLANUEVA, Luis F. Aguillar. Política Pública Una visión panorámica. Bolivia: PNUD, 2012. 